\title{
As Competências EaD de alunos concluintes do Ensino Médio: resultados do instrumento de coleta de dados
}

\author{
Deividi Schumacher Velho, FACOS, deividivelho@gmail.com \\ Andrio dos Santos Pinto, FACOS, andriosp@gmail.com
}

\begin{abstract}
Resumo. Com o avanço da tecnologia, multiplicaram-se as possibilidades de aprendizagem através deste meio, e a EaD surge então como uma modalidade educacional de grande potencial, permitindo com que o aluno desenvolva a sua autoaprendizagem. Diante disso, o presente artigo tem por objetivo apresentar resultados do instrumento de coleta de dados, que buscou identificar quais os alunos concluintes do Ensino Médio, possuem as competências mapeadas por Behar e que são necessárias para o ingresso em um curso na modalidade à distância. Este instrumento foi elaborado refletindo situações vivenciadas pelos alunos, os quais devem servir de base para futuros confrontamentos.
\end{abstract}

Palavras-chave: Educação a Distância, competências, aprendizagens.

\begin{abstract}
With the advancement of technology have multiplied the possibilities for learning through this medium, and distance education emerges as an educational modality with great potential, allowing the student to develop their self-learning. Therefore, this article aims to present the results of data collection instrument, which sought to identify which students graduating from high school, have skills mapped by Behar and are required for entrance into a course in distance mode. This instrument was prepared reflecting situations experienced by students, which should be the basis for future confrontations.
\end{abstract}

Keywords: Distance education, competences, learning.

\section{Introdução}

Atualmente as possibilidades de aprendizagens através da Internet são complexas e variadas, pois o seu uso auxilia, por exemplo, em pesquisas escolares, práticas de leitura/escrita, interação nas redes sociais e em Ambientes Virtuais de Aprendizagem (AVA), propiciando um espaço interativo e dialógico. A questão a ser dita é que hoje, as Tecnologias da Informação e Comunicação (TIC) se disseminaram com intensa rapidez, beneficiando o avanço da Educação a Distância $(\mathrm{EaD})$, que por sinal, nos últimos anos teve um grande avanço no cenário educacional brasileiro. Conforme Peters (2002, p. 41), "[...] está ocorrendo uma revolução pedagógica na educação a distância: o uso crescente de ambientes informatizados de aprendizagem e da rede."

As gerações que nascem e vivem em meio ao mundo tecnológico estão desenvolvendo novas formas de pensar, agir, aprender e ser, toda essa mudança está ocorrendo rapidamente, causando também uma mudança em ambientes escolares e modos de aprendizagens, pois agora contam com essas ferramentas tecnológicas, o que acaba beneficiando a EaD. 
Com todo esse desenvolvimento, a EaD surge como uma modalidade educacional de grande potencial, viabilizando a demanda de ensino no Brasil. De acordo com a Associação Brasileira de Educação a Distância (ABED) em seu relatório analítico de 2011, o número de estudantes que optam por cursos online está em crescimento, porém, deve-se ter cuidado que nem todos os cursos na modalidade à distância tem qualidade para dar suporte à aprendizagem.

No entanto, existem pontos que devem ser levantados quando se trata de $\mathrm{EaD}$, onde os alunos destes processos necessitam demonstrar conhecimentos, habilidades e atitudes próprias, onde as quais podem ser identificadas com as competências específicas elencadas por Behar et al. (2013), pois para o aluno da EaD, faz-se necessário um domínio próprio das tecnologias e suas possibilidades.

Realizando uma análise das características da $\mathrm{EaD}$, percebe-se que as mesmas se diferenciam muito da modalidade presencial, elas podem até terem o mesmo objetivo: a construção do conhecimento, portanto, o aluno EaD elenca diferentes tipos de competências em relação a alunos do ensino presencial. Moore e Kearsley (2008, p.1), em relação ao aluno, mostram que, ser um aluno a distância é bem diferente, pois o mesmo necessita ter diferentes aptidões.

Desta forma, o presente artigo busca apresentar dados coletados através de um questionário online. Após os dados coletados é realizado um cruzamento com a roda de competências, na qual leva em consideração as onze competências de Behar et al. (2013) organizadas em graus de dificuldades. Com isso, o objetivo foi identificar quais os alunos concluintes do Ensino Médio possuíam as competências necessárias para ingressar em um curso na modalidade a distância segundo Behar et al. (2013).

\section{Educação a Distância}

Consideram-se, atualmente, duas modalidades de ensino: a presencial e à distância. Fava (2012) apresenta a presencial, onde em um mesmo espaço, professores e alunos convivem, ou seja, chamado de sala de aula, e esses encontros são realizados ao mesmo tempo, também conhecido como ensino convencional. Moore e Kearsley (2010) falam que, a modalidade à distância, é efetivada com o uso intenso das TIC, onde o professor e aluno estão separados fisicamente e seus encontros não tem tempo certo para ocorrer.

O conceito de Educação a Distância no Brasil é definido oficialmente no Decreto $n^{0} 5.622$ de 19 de dezembro de 2005 (BRASIL, 2005):

Art. $1^{\circ}$ Para os fins deste Decreto, caracteriza-se a Educação a Distância como modalidade educacional na qual a mediação didático-pedagógica nos processos de ensino e aprendizagem ocorre com a utilização de meios e tecnologias de informação e comunicação, com estudantes e professores desenvolvendo atividades educativas em lugares ou tempos diversos.

Historicamente, a educação a distância iniciou com o ensino por correspondência, que utilizava documentação impressa para veicular a informação.

Moore e Kearsley (2010) explicam que, a educação a distância é o aprendizado planejado, que ocorre normalmente em um lugar diferente do local do ensino, exigindo técnicas especiais de criação dos cursos e de instrução, de comunicação por meio das tecnologias, disposições organizacionais e administrativas especiais. É necessário 
refletir também acerca dos papéis de professor, tutor e aluno, para que se entenda melhor o papel de cada um dentro da modalidade EaD. Desta maneira, busca-se apresentar brevemente um panorama de cada um.

O papel do professor é muito importante, pois cabe a ele organizar e aplicar um modelo de arquitetura pedagógica, que seja adequada à modalidade, e que também consiga acompanhar as mudanças sociais e educacionais, que possam vir a interferir na prática pedagógica, conforme apresenta Behar et al. (2013).

Talvez a maior diferença da modalidade presencial da modalidade a distância seja o papel de tutor, presente nesta modalidade. O tutor atua junto ao professor, participando do processo de ensino e aprendizagem, mais especificamente acompanhando a construção do aluno. De acordo ainda com as autoras, o tutor exerce papel de mediador e atua como professor auxiliar, acompanhando o processo de aprendizagem dos alunos por meio das TIC.

Assim como os demais perfis, o perfil de aluno também sofreu mudanças, gerados pelo uso das tecnologias. Com isso, gerou-se um impacto na educação, alterando os espaços escolares e recursos utilizados para o ensino.

\section{Ensino por competências}

O currículo tradicional hoje é baseado em conteúdo e segundo Behar et al. (2013), muitas vezes são colocados obstáculos na identificação do significado em relação ao contexto que os alunos estão. Isto porque, as provas ou verificações servem como forma de avaliação, e com isso, destaca-se a memorização em vez da aprendizagem, resumindo em pouca construção do conhecimento, porque não há uma presença ativa do aluno no processo.

Perrenoud e Thurler (2002) argumentam que este processo não é simplesmente só absorver as informações, mas também compreendê-las, mobilizá-las e utilizá-las em situações práticas também. Entretanto, cabe a escola a função de realizar estas ações, seja por atividades interdisciplinares, sejam por disciplinas que coloquem os alunos diante às situações problemas, levando os mesmos à mobilização dos recursos. É preciso mudar a perspectiva que está centrada no professor e no ensino, para uma perspectiva focada no aluno e na aprendizagem.

Para que o aluno aprenda, Behar et al. (2013) falam que é necessário levar à prática pedagógica, atividades que permitam ao aluno aprender perguntando, pesquisando, trabalhando coletivamente, planejando e organizando, o que torna o ambiente motivador, fazendo com que o aluno construa conhecimentos e que as suas habilidades sejam aprimoradas em relação a materiais e recursos utilizados, e por fim as atitudes, pois não adianta de nada, mobilizar os conhecimentos e as habilidades se não ter as atitudes para realizá-las.

Das muitas situações de aprendizagens em que o aluno é inserido, faz parte dos mesmos mobilizarem os elementos das competências. Segundo Gaspar (2004) a aprendizagem de competências exige uma atitude construtivista, prevendo um percurso com momentos de confronto entre o que já existe e o que é novo, onde obriga o aluno a perceber e valorizar a diferença. 
É importante também salientar, que as competências são muitas vezes entendidas de forma incorreta, como uma pedagogia de objetivos, onde o foco principal é o desempenho, e como uma potencialidade genérica comum, como afirma Perrenoud (1999). Por mais que alunos e professores possam ter objetivos a alcançar ao longo da formação, isso não justifica que são competentes, isso também porque todos os indivíduos possuem condições para aprender e as competências necessitam deste processo para serem construídas. Gaspar (2004) também complementa que as competências não são ensinadas, mas que são criadas condições que estimulam a sua construção, colocando o aluno em situações complexas, onde exige do mesmo a mobilização de seus conhecimentos para compreender, elucidar, resolver, desenvolver e tomar decisão diante de uma situação problema.

\section{Competências na EaD}

De acordo com o avanço da tecnologia na educação e a Internet para suporte à EaD, percebe-se uma mudança nos perfis dos alunos, conforme Behar et al. (2013), criando novas formas de aprender e fazendo com que as práticas pedagógicas sejam revistas.

Coll e Monereo (2010) afirmam que, com o impacto das TIC na educação, um fenômeno muito mais amplo do que imaginamos, surgem novas formas da sociedade atual de se comunicar, trabalhar, relacionar-se, aprender, pensar, resumindo, de se viver diferente.

Assim sendo, os meios tecnológicos atuais permitem com que os alunos, professores e tutores tenham uma maior mobilidade e agilidade, sendo que estes podem estar usufruindo destes recursos em qualquer lugar, permitindo-os a construção e aprimoramento de seus conhecimentos e metodologias. No entanto, para que sejam desenvolvidas as competências, requer-se que as estratégias educacionais continuem sempre se aperfeiçoando, ou seja, buscando possibilidades novas para a construção do conhecimento dos alunos.

\subsection{Competências do aluno EaD}

Conforme apresentado anteriormente, a EaD está surgindo cada vez mais forte, isso porque teve um aumento significativo de $500 \%$ em 2010 quando comparado com o ano de 2000 somente nos cursos de graduação (Brasil, 2010). Isso também gerou as discussões, com os processos que esta modalidade tem, e também os sujeitos que a compõem. Diante dessas e muitas outras discussões surgem as competências dos discentes para a $\mathrm{EaD}$.

Para Behar et al. (2013), o estudante necessita de acompanhamento da equipe pedagógica para que o mesmo desenvolva as competências. As autoras também frisam que este acompanhamento poderá ser realizado através de interações por meio de uso dos AVAs e mapearam as seguintes competências aos alunos que pertencem à modalidade à distância, conforme a (Tabela 1):

Tabela 1- Competências do aluno EaD

FLUÊNCIA DIGITAL: Está ligada à utilização da tecnologia de modo que o sujeito se sinta digitalmente ativo/participante dos avanços tecnológicos. A fluência possibilita não só o uso, mas também a criação e produção de conteúdos/materiais. 
AUTONOMIA: Para Piaget (1987), autonomia significa ser governado por si mesmo. É o oposto de heteronomia, que significa que uma pessoa é governada por outra pessoa.

REFLEXÃO: Está baseada na abstração para refletir e analisar criticamente situações, atividades e modos de agir.

ORGANIZAÇÃO: Relaciona-se com a ordenação, estruturação e sistematização de atividades, materiais e grupos.

COMUNICAÇÃO: Está fundamentada na clareza e na objetividade da expressão oral, gestual e escrita.

ADMINISTRAÇÃO DO TEMPO: É pautada no cumprimento da agenda, conciliar atividades de compromissos para a gestão das atividades, atingindo as prioridades, metas e objetivos.

TRABALHO EM EQUIPE: O trabalho em equipe contempla as relações intra e interpessoal, as quais permitem ao sujeito expressar e comunicar, de modo adequado, seus sentimentos, desejos, opiniões e expectativas. Além disso, evidencia condutas interpessoais, destreza para interagir com outras pessoas de forma socialmente aceitável e valorizada, podendo, assim, trazer benefícios aos participantes nos momentos de interação. Esses elementos podem, ainda, ser complementados sob a ótica afetiva, isso porque a complexidade das relações sociais também requer a capacidade de perceber e fazer distinções no humor, nas intenções, nas motivações e nos sentimentos de outras pessoas.

MOTIVAÇÃO: Estabelece as condições para manter a motivação entre pares e consigo mesmo, sendo um facilitador dos processos. Da mesma forma, ser capaz de acolher as dificuldades do outro, incentivando-o a permanecer e concluir uma atividade, sendo ativo e participativo. Ser capaz de lidar com as próprias dificuldades.

PRESENCIALIDADE VIRTUAL: Tem relação com a presença no ambiente virtual através da interação com os colegas e da realização das atividades.

AUTOAVALIAÇÃ O: Trata-se da compreensão acerca do desenvolvimento do próprio processo de aprendizagem, a fim de colaborar ou avaliar as atividades propostas.

FLEXIBILIDADE: Consegue lidar com diferentes necessidades, examinando e interpretando as possibilidades de ações, bem como mudanças de opinião e atitudes.

\section{Metodologia}

Esta pesquisa teve natureza qualiquanti, ou seja, teve caráter qualitativo e quantitativo, cuja principal finalidade é esclarecer, desenvolver e modificar conceitos e ideias, com vistas na formulação de problemas mais precisos ou hipóteses pesquisáveis para estudos posteriores no assunto. Estes dois tipos de pesquisas foram escolhidas, porque elas se completam, facilitando assim a análise dos dados, conforme afirmam Lakatos e Marconi (2010).

Toda a pesquisa necessita de um público alvo, pois é com base em um conjunto de pessoas que os dados são coletados e analisados. Neste caso, o público alvo foram alunos concluintes do Ensino Médio das cinco escolas pertencentes a cidade de Osório, no Litoral Norte do Rio Grande do Sul, que responderam ao questionário elaborado no Google Drive e que está disponível através do link: $<$ http://goo.gl/5tPpYn $>$. Segundo Prodanov e Freitas (2013), o questionário é um instrumento utilizado quando se objetiva atingir certo número de pessoas, formado de um conjunto de questões formuladas pelo pesquisador. Esta pesquisa busca analisar o perfil de competências desses alunos de Ensino Médio para um possível ingresso dos mesmos na modalidade EaD.

Através das competências específicas de Behar et al. (2013) elencadas na seção anterior, foram pensadas e elaboradas diversas situações vivenciadas diariamente pelos 
estudantes e elencados índices de $0 \%$ a $100 \%$ para cada uma destas. A partir daí, foram atreladas situações a cada uma das competências correspondentes (Tabela 2), o que permitiu uma análise mais fina, com resultados mais fidedignos, pois a maioria das competências obtiveram mais de uma situação vinculada.

Tabela 2 - Associações feitas entre as questões do questionário e as competências

\begin{tabular}{|c|c|}
\hline Competências & Questões \\
\hline FLUÊNCIA DIGITAL & $3,4,5,6,7,8$ e 13. \\
\hline AUTONOMIA & $7,8,10,11,14,15,16,17$ e 18. \\
\hline REFLEX̃̃O & $8,12,14,15,16$ e 17. \\
\hline ORGANIZAÇÃO & $10,11,13,14,15,16,17$ e 18. \\
\hline COMUNICAÇÃO & 8,16 e 17. \\
\hline ADMINISTRAÇÃO DO TEMPO & 11 e 18. \\
\hline TRABALHO EM EQUIPE & 9,10 e 15. \\
\hline MOTIVAÇÃO & 12,15 e 17. \\
\hline PRESENCIALIDADE VIRTUAL & $5,6,13$ e 16. \\
\hline AUTOAVALIAÇÃO & 14. \\
\hline FLEXIBILIDADE & 15. \\
\hline
\end{tabular}

Partindo deste pressuposto, se adaptou a roda das doze competências de Silva (2012), conforme (Figura 1), levando em consideração as onze competências de Behar et al. (2013), organizando-as dentro dos graus de dificuldade, na qual se representa através das cores: verde (competências básicas); amarelo (competências medianas); e vermelho (competências de difícil desenvolvimento), e representou-as com os índices de $70 \%, 60 \%$ e $50 \%$, respectivamente. Estes índices foram elaborados para demonstrar de forma quantificada os resultados obtidos pelo instrumento de coleta.

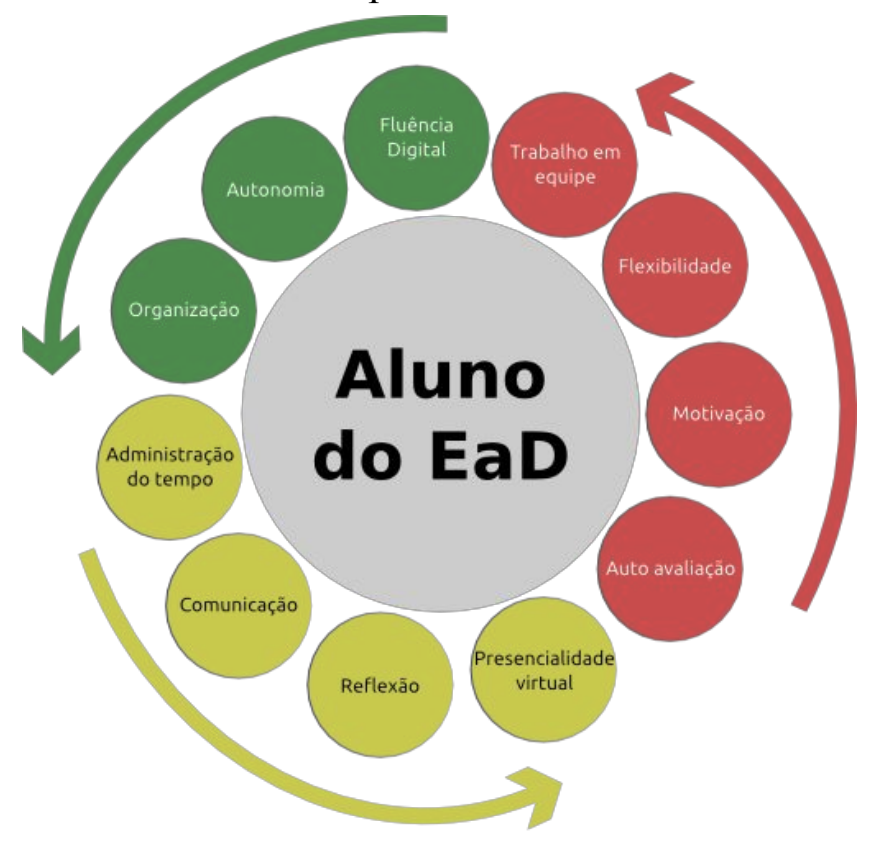

Figura 1- Roda das onze competências Adaptado de Silva (2012) 


\section{Resultados}

Nesta seção são apresentados os dados coletados pelo instrumento de coleta de dados, com o objetivo de demonstrar quais alunos tendem a ter as competências específicas elencadas por Behar et al. (2013) para ingressar em um curso à distância. O instrumento de coleta de dados foi aplicado em todas as escolas de Ensino Médio do município de Osório - RS, sendo destas quatro escolas públicas e apenas uma privada, com alunos concluintes deste nível de ensino, onde se obteve 88 respostas, isso porque foi aplicado com uma turma de cada escola.

Destas 88 respostas, $52 \%$ são do sexo masculino e $48 \%$ do sexo feminino como podemos observar na (Figura 2), também vale ressaltar que esse é um total geral, portanto de escola para escola esses dados variam.

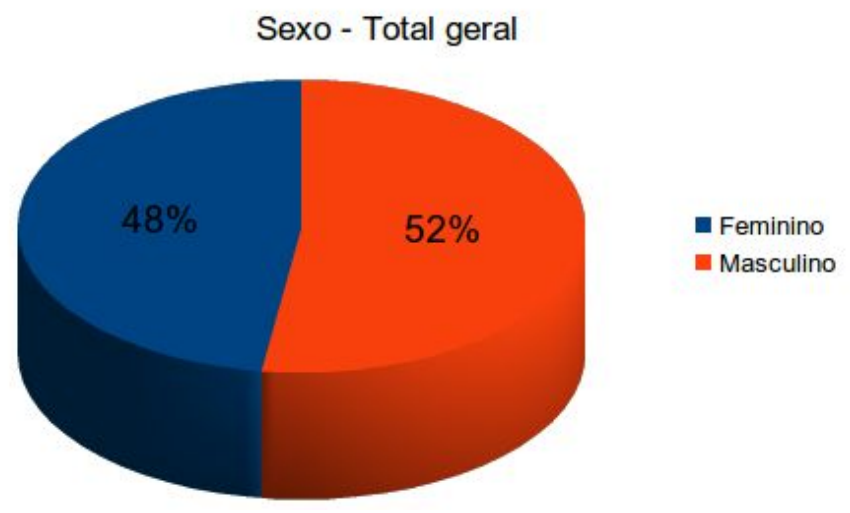

Figura 2 - Gráfico do sexo total

$\mathrm{Na}$ (Figura 3), é possível analisar a média das onze competências por escola.

Média geral das competências por escola

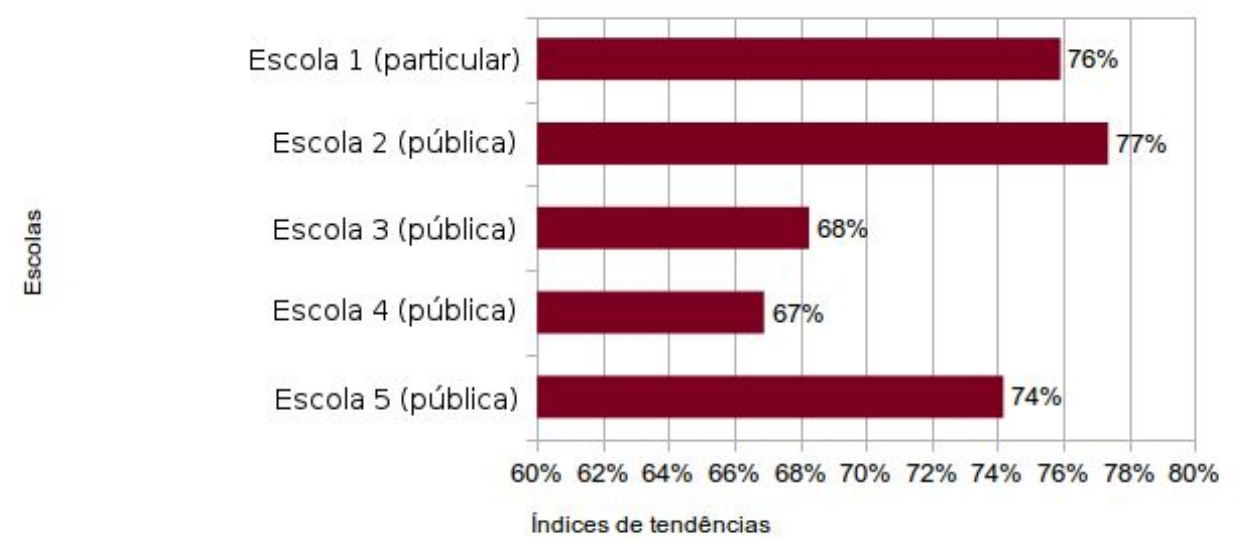

Figura 3 - Gráfico de média geral das competências por escola

Ao observarmos a (Figura 3) é possível analisar que o intervalo do índice é de $10 \%$, entre o maior e o menor índice. Os estudantes da Escola 2 (pública) alcançaram o maior índice na média das competências, com $77 \%$. Já os estudantes da Escola 1 (particular) alcançaram o segundo maior índice na média das competências, com $76 \%$. O terceiro índice ficou com os estudantes da Escola 5 (pública). O quarto índice, com os 
estudantes da Escola 3 (pública) que tiveram 68\%, ou seja, 1\% a mais que o menor índice, obtido pelos estudantes da Escola 4 (pública), com 67\%.

Na Figura 4 foi realizada a média geral das competências de forma individual e também a média das mesmas em um índice final.

\section{Média geral por competência}

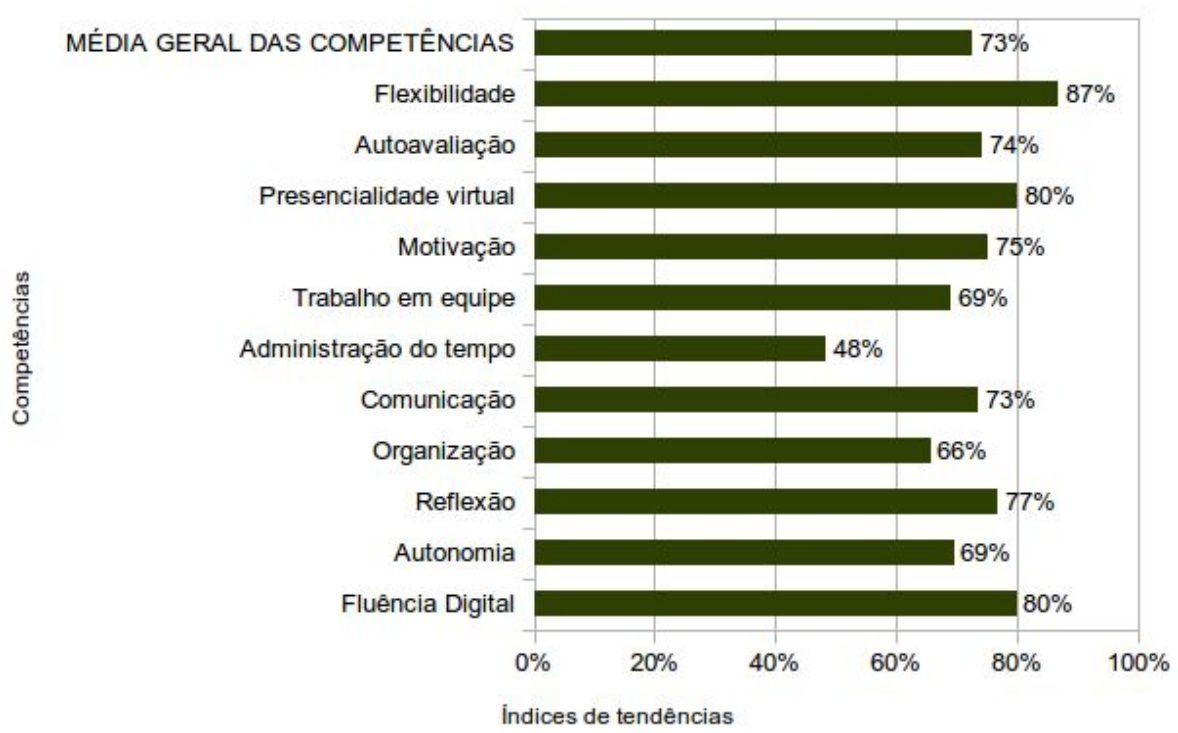

Figura 4 - Gráfico de média geral por competência

$\mathrm{Na}$ (Figura 4) foram obtidos os índices finais de cada competência e também uma média dos mesmos. A seguir, se apresentam em ordem decrescente os índices para as competências:

1. Flexibilidade: $87 \%$;

2. Fluência Digital e Presencialidade virtual: $80 \%$;

3. Reflexão: $77 \%$;

4. Motivação: $75 \%$;

5. Autoavaliação: $74 \%$;

6. Comunicação: $73 \%$;

7. Autonomia e Trabalho em equipe: $69 \%$;

8. Organização: $66 \%$; e

9. Administração do tempo: $48 \%$.

Aplicando a roda de competências é possível analisar que, entre as competências básicas somente a Fluência Digital atinge o mínimo. Já nas competências consideradas medianas, somente a Administração do Tempo não atingiu o índice mínimo. Nas competências de difícil desenvolvimento, todas foram alcançadas. O que também foi uma surpresa para o pesquisador.

Portanto, fazendo uma análise mais geral, podemos notar que a Escola 2 (pública), na média das competências, ficou melhor que a Escola 1 (particular), e que somente a competência Administração do Tempo não alcançou os índices necessários para a modalidade EaD. 


\section{Considerações finais}

Primeiramente, se faz necessário registrar o quão enriquecedor e desafiador foi à realização deste trabalho. Um processo longo, como a busca de embasamento teórico, a construção de um método para a coleta de dados, técnicas para a análise dos dados e enfim a conclusão. Com o intuito de finalizar a etapa do estudo sem dar um ponto final, resume-se alguns pontos importantes desde trabalho, buscando não só mostrar o caminho que foi percorrido, mas também poder trazer algumas reflexões, que possam contribuir em trabalhos futuros.

Este estudo buscou inicialmente um alicerce, portanto, foi realizada uma pesquisa bibliográfica com os principais assuntos que norteavam este trabalho, tais como: EaD, Aluno EaD e competências EaD. A partir destas informações levantadas foi possível elencar os princípios deste percurso, sendo possível organizar a metodologia de forma clara e objetiva. Através desta, se constituiu a primeira etapa, onde foi a elaboração do instrumento de coleta de dados. A segunda etapa, foram atreladas situações a cada uma das competências correspondentes, como a maioria das competências obtiveram mais de uma situação vinculada, permitiu-se então uma análise mais fina, com resultados mais concretos. A terceira e última etapa aconteceu a análise de dados, levando em consideração a roda das competências adaptada de Silva (2012), com seus respectivos índices de graus de dificuldade, para que então pudessem ser feitos os devidos confrontos.

O estudo por competências se fez necessário, pois busca auxiliar os alunos nas atividades. Cada vez mais se precisa de alunos com competências suficientes para realizar a gestão da sua aprendizagem. Portanto, entender quais são as competências necessárias, pode facilitar a construção do conhecimento, sendo relevante para alunos envolvidos deste processo. Com isso, esta pesquisa teve como objetivo analisar o perfil de competências desses alunos de Ensino Médio para um possível ingresso dos mesmos na modalidade EaD. No entanto, esses alunos devem ter em mente, que atuar nesta modalidade é diferente da modalidade presencial, pois os elementos do CHA se alteram de uma para a outra. Encaminhando-se para o final ainda com questionamentos a espera de respostas, no entanto vão servir de motivações para pesquisas posteriores.

Conclui-se que, a importância de continuar os estudos sobre as competências, realizando novos métodos e estratégias para realização desta pesquisa, o que não foi possível neste estudo. Além disso, é interessante o desenvolvimento de uma ferramenta capaz de realizar de mapeamento de forma automatizada.

\section{Referências}

BEHAR, Patricia Alejandra. Competências em educação a distância. Penso Editora, 2013.

BRASIL. Decreto 5.622, de 19 de dezembro de 2005. Regulamenta o artigo 80 da Lei no 9.394, de 20 de dezembro de 1996, que estabelece as diretrizes e bases da educação nacional. Diário Oficial [da] República Federativa do Brasil. Brasília, DF, 20 dez. 2005. Disponível em: . Acesso em: 15 jul. 2015.

BRASIL. Censo da Educação Superior. INEP/MEC, 2010. 
Censo EAD.BR. Relatório analítico da aprendizagem a distância no Brasil 2011. São Paulo: Pearson Education do Brasil, 2012. ABED - Associação Brasileira de Educação a Distância. Disponível em: $<$ http://www.abed.org. br/censoead/censo2012.pdf>. Acesso em: 10 jun. 2013.

COOL, César; MONEREO, Charles. Psicologia da educação virtual: aprender e ensinar com as tecnologias da informação e da comunicação. Porto Alegre: Artmed, 2010.

FAVA, Rui. Educação 3.0: como ensinar estudantes com culturas tão diferentes. 2011.

GASPAR, Ivone. Competências em questão: Contributo para a formação de professores. 2004. Disponível em: <https://repositorioaberto.uab.pt/bitstream/ 10400.2/158/1/Discursos\%E2\%80\%93Forma\%C3\%A7\%C3\%A3o\%20de\%20Professor es55-71.pdf $>$. Acesso em: 15 abr. 2013.

MARCONI, Marina de Andrade; LAKATOS, Eva Maria. Fundamentos de metodologia científica. In: Fundamentos de metodologia científica. Atlas, 2010.

MOORE, Michael G. et al. Educação a distância: uma visão integrada. Cengage Learning, 2007.

PERRENOUD, Philippe; THURLER, Monica Gather. As competências para ensinar no século XXI: a formação dos professores e o desafio da avaliação. Artmed, 2002.

PERRENOUD, Philippe. Construir competências é virar as costas aos saberes. Pátio. Revista Pedagógica, v. 11, p. 15-19, 1999.

PETERS, Otto. A educação a distância em transição: tendências e desafios. Editora Unisinos, 2004.

PIAGET, Jean. O Nascimento da Inteligência na Criança”. Suíça: Editora Guanabara, 1987.

PRODANOV, Cleber Cristiano; DE FREITAS, Ernani Cesar. Metodologia do Trabalho Científico: Métodos e Técnicas da Pesquisa e do Trabalho Acadêmico-2 ${ }^{\mathrm{a}}$ Edição. Editora Feevale, 2013.

SILVA, Ketia Kellen Araújo da. Mapeamento de competências: um foco no aluno da educação a distância. Porto Alegre, 2012.

ZABALA, Antoni; ARNAU, Laia. Como aprender e ensinar competências. Tradução de Carlos Henrique Lucas Lima. Porto Alegre: Artmed, 2010. 